\title{
Analysis and Diagnosis of Water Environment Pollution Sources of Tonggu Lake in Fuling District, Chongqing City
}

\author{
Xiaolei Zheng 1,*, Tao Yang ${ }^{2}$, Gaoxiang Liu $^{3}$, \\ ${ }^{1}$ Chongqing Jianzhu college, Associate professor, Chongqing, China, 400039 \\ ${ }^{2}$ Tianjin University, PhD; Chongqing Fuling District Xincheng District Management Committee, Senior engineer, Chongqing,China, \\ 408000 \\ ${ }^{3}$ College of Environment and Ecology, Chongqing University, PhD, Chongqing, China, 400045
}

\begin{abstract}
As an important urban lake in Fuling District, Chongqing City, there is water blooms in Tonggu Lake, which affect the ecological environment. This study analyzed and studied the external and internal status of water pollution through site survey, water quality testing and analysis, and laboratory data analysis, and diagnosed the water environment of Tonggu Lake, which is helpful for providing strong data support for the follow-up solution to the problem of water bloom in Tonggu Lake.
\end{abstract}

\section{Research Background}

Urban lakes is extremely important for maintaining the safety of water, ecology and environment, promoting ecological balance, and improving the living environment of the people ${ }^{[1]}$. Tonggu Lake, located in Fuling District, Chongqing City, is an important part of the green barrier construction in Fuling District. However, the water quality of Tonggu Lake is generally poor, the water supply for the lake is scant, and the water replacement cycle is long due to the acceleration of urbanization in recent years, lacking of effective protection of the lake in the development process. At the same time, due to the input of mustard waste water and non-point source pollution, the water body of Tonggu Lake has turned black, and the growth potential of algae is large, and water blooms are common in summer. In order to improve the water environment management of Tonggu Lake, actively rectify the lake eutrophication and river black and odor problems, promote the improvement of the ecological environment, the research is specially conducted to provide reference for other urban lake pollution management.

\section{Analysis of current situation of water environment in Tonggu Lake}

Tonggu Lake, as a typical urban lake, there is a problem of poor fluidity due to closed water body in general.

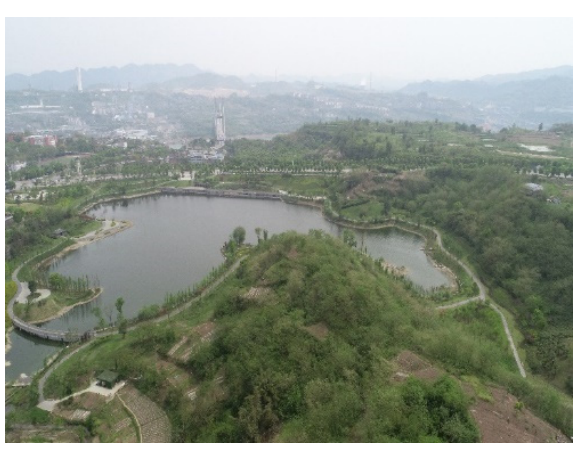

Figure 1. Aerial view of Tonggu Lake

\subsection{Current status of external source pollution}

The main sources of replenishment for the Tonggu Lake are the Zhujiagou Reservoir in upstream area and natural precipitation, including runoff from farmland. The Zhujiagou effluent is at Level A Standard (TP $0.15 \mathrm{mg} / \mathrm{L}$; $\mathrm{TN} 1.13 \mathrm{mg} / \mathrm{L}$ ). When incoming water pipeline from Zhujiaku is damaged, for the external sewage and rainwater or initial rainwater on roads that have not been intercepted, as well as the farmland runoff, the nutrient elements such as N, P, etc. carried by them are destroyed by the ecosystem, and the hydro-fluctuation belt that loses the function of plant interception enters Tonggu Lake, which form the external source pollution to Tonggu Lake.

In order to investigate the impact of external source pollution on the water environment quality of Tonggu Lake, the surface water quality of different waters in Tonggu Lake was sampled and tested at different points mainly for the content of TP, COD, TN, NH4+-N, NO3$\mathrm{N}$ and $\mathrm{Chla}^{[2]}$. According to the water quality detection and analysis of different sampling points, and according to the spatial distribution of $\mathrm{COD}, \mathrm{TP}, \mathrm{TN}$ and other

\footnotetext{
${ }^{*}$ Corresponding author: xiaoleitaotao@126.com
} 
indicators under the influence of external water replenishment, it is found that the COD gradually decreases along the water inlet direction. For external water supply that flows from Zhujiagou Reservoir through green land and farmland into Tonggu Lake, Nonpoint source pollution and runoff entangled by its agricultural activities are the main reasons for the higher TP content in Tonggu Lake. And it leads to the phenomenon that the TN, COD, NH4+-N, and Chla values diffuse into the lake along with the inlet, and the pollutants are high at the inlet end and low in the middle of the lake. The Chla value in the surface water is much higher than the overlying water, which shows that external source pollution is the main source of eutrophication of Tonggu Lake.

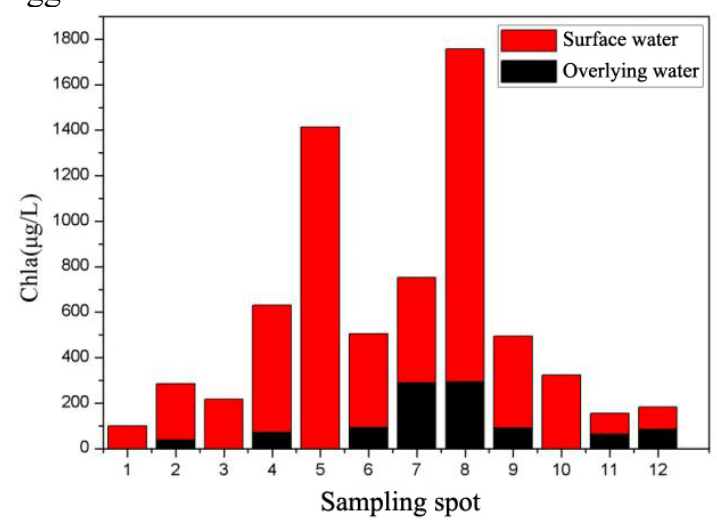

Figure 2. Chla content in the surface water and the overlying water

The external source pollution of Tonggu Lake is located around the lake and in the exposed and fluctuating zones around the lake that are prone to seasonal and time fluctuations in the water level of the lake. Through on-site surveys, most of the vegetation is missing, and there are large-scale hydro-fluctuation belt around the waters of the Tonggu Lake wetland, which greatly reduces the ability to intercept external non-point source pollution.

In general, the spatial distribution of water quality in Tonggu Lake is uneven, which may be related to the influx and diffusion of external water. The surface water quality at the mouth of the lake has deteriorated at the most, and the water quality in the center of the lake is less affected by external pollution. At the same time, higher nutrient levels indicate that the Tonggu Lake is seriously polluted, and farmland runoff and external water supply have a greater impact on the water quality of the lake area. There is a large area of hydro-fluctuation belt around the water area, which greatly reduces the interception capacity of non-point source pollution. The Chla content of surface water is much higher than that of overlying water, and both exceed the standard for eutrophication. Therefore, corresponding measures need to be taken to reduce the impact of external pollution on the water quality of Tonggu Lake.

\subsection{Current status of internal source pollution}

Internal pollution is the main pollution source of rivers and lakes. Long-term external input and the deposition of biological residues have led to the deposition of a large amount of organic matter and nitrogen-containing substances at the bottom of the river. At the same time, the release of nutrients from the bottom mud plays a very important role in the reproduction and growth of phytoplankton $^{[3][4]}$. The exchange of nutrients among the sediment, interstitial water and overlying water has an important impact on the nutrient load and the formation of eutrophication in lake water.

Tonggu Lake has a low water flow speed, slow water renewal, and high chlorophyll a content. Therefore, in order to understand the temporal and spatial distribution of nutrients among surface water, overlying water, and interstitial water, the sediments at different monitoring points are sampled and monitored and the situation of internal source pollution is analyzed. Through testing of samples in laboratory, it was found that the nutrient salt in Tonggu Lake showed a trend of interstitial water $>$ overlying water $>$ surface water. The release potential of nutrients in sediment is large, and the $\mathrm{TN}$ and ammonia nitrogen in interstitial water are significantly higher than the surface water. Among them, the relatively higher content of NH4+-N will be toxic to the fish in the lake. The measurement found that the content of NH4+-N in interstitial water in some waters is much greater than that of surface water and overlying water. The proportion of NO3-N content in this water has dropped significantly at this point, indicating that the content of organic matter in the sediments of the waters is relatively high with a trend of spreading to interstitial water continuously.
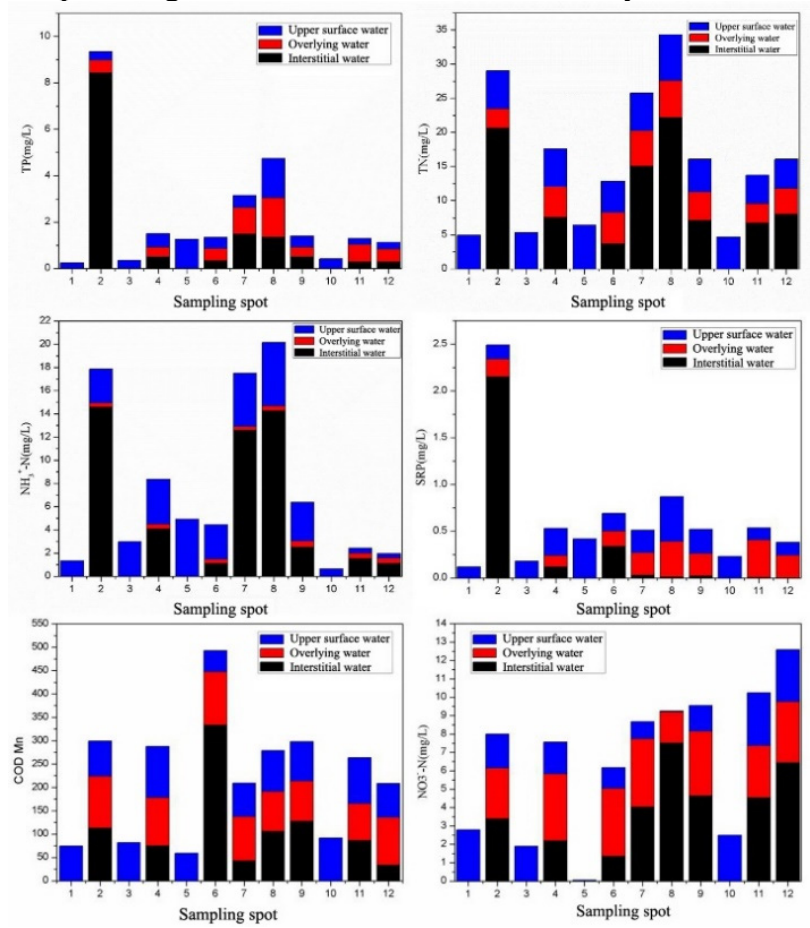

Figure 3. Water quality detection of surface water, overlying water and interstitial water

Through data analysis, the TP concentration of the interstitial water along the depth is greater than $4.5 \mathrm{mg} / \mathrm{L}$, but there is no increasing trend along the depth, which is higher than the Class V standard of surface water (TP 0.2 $\mathrm{mg} / \mathrm{L})$. TN has an obvious increasing trend along the depth of the water body, and the maximum TN value can reach $45 \mathrm{mg} / \mathrm{L}$ within $35 \mathrm{~cm}$ of the surface layer, which is 
higher than the Class V standard of surface water (TN 2.0 $\mathrm{mg} / \mathrm{L}$ ). In addition, sediments also affect the content of heavy metals in lake water bodies, and the copper, chromium, and zinc are detected. The content of copper and lead increases along the depth of the water body, the content of chromium fluctuates along the depth of the water body, and the content of zinc decreases along the depth of the water body.

In summary: combined with the analysis of the sediments in Tonggu Lake, we can know from the water quality data that the contents of TP, TN, NH4+-N, NO3-$\mathrm{N}$, COD and SRP are as follows: interstitial water> overlying water $>$ surface water, of which TN and NH4+$\mathrm{N}$ content in interstitial water is significantly higher than that of the surface layer, and the data in front of the dam is significantly higher than other sites. The release potential of nutrients in sediment is huge. In terms of the design of water environment treatment and water quality improvement project for Tonggu Lake, treatment measures should be proposed for internal pollution.

\section{Diagnosis of water environment problems}

\subsection{Diagnosis of eutrophication}

Through on-site sampling of Tonggu Lake, the water quality monitoring indicators of Tonggu Lake include COD, TP, TN, NH4+-N, NO3-N and Chla. The water quality results of the surface water at each sampling point are shown in Figure 4.
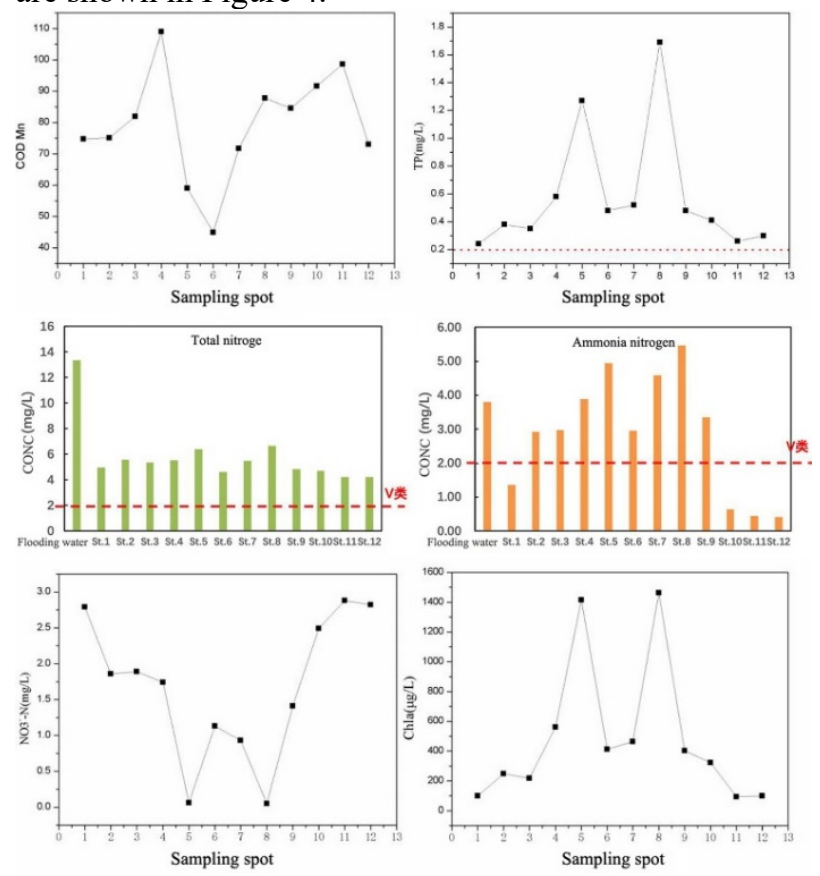

Figure 4. Surface water quality results of the water quality monitoring sampling points of Tonggu Lake

In the water quality indicators of Tonggu Lake, the concentration of TP is in the range form $0.22 \mathrm{mg} / \mathrm{L}$ to 1.70 $\mathrm{mg} / \mathrm{L}$, which is $1-9$ times higher than the standard of surface water $(0.2 \mathrm{mg} / \mathrm{L})$; the concentration of TN is in the range of $4.0-13.5 \mathrm{mg} / \mathrm{L}$, which is $2-7$ times higher than the standard of surface water $(2.0 \mathrm{mg} / \mathrm{L})$; the concentration of NH4+-N ranges from 0.3 to $5.4 \mathrm{mg} / \mathrm{L}$, and the concentration fluctuates significantly with spatial changes. The degree of conversion of nitrogen-containing organic matter is higher; the concentration range of chlorophyll content (Chla) in water is $80-150 \mu \mathrm{g} / \mathrm{L}$, which far exceeds the eutrophication standard (Chla $>10 \mu \mathrm{g} / \mathrm{L})$.

The main phytoplankton in the water body are: colony Microcystis, Chlorella, Crescentia, and Pegasus, and there is the potential threat of algal blooms.

According to GB3838-2002 《Environmental Quality Standards for Surface Water 》 [5] and the water environmental assessment of Tonggu Lake, the water quality of it is generally poor, and the water quality indicators of each sampling point are lower than the Class $\mathrm{V}$ standard. Among them, the surface water TP (total phosphorus) of the whole lake exceeds the water quality of surface water Class V standard by 1-9 times, and TN (total nitrogen) exceeds 2-7 times. TP is the priority pollutant of Tonggu Lake, and the Chla content far exceeds the eutrophication standard. There is a higher possibility of algal blooms. Through the monitoring and analysis of the water quality of Tonggu Lake, the lowest Chla content in the sample points was $92 \mu \mathrm{g} / \mathrm{L}$ and the highest was $1463 \mu \mathrm{g} / \mathrm{L}$. It can be seen that the water quality of Tonggu Lake far exceeds the degree of eutrophication. Moreover, the dominant algae in Tonggu Lake are the Microcystis and Chlorella, which pose a huge potential threat of severe algal blooms.

\subsection{Analysis of pollution structure}

The pollution load of Tonggu Lake mainly comes from external pollution (external water replenishment and agricultural runoff) and internal pollution (the release of nitrogen and phosphorus from the sediment). Through the establishment of the total phosphorus dynamic model in Tonggu Lake and model calculations, a preliminary assessment of the external and internal pollution of the Tonggu Lake wetland was carried out. The results show that the total phosphorus emission from point sources, farmland non-point sources, etc. is $61.0 \mathrm{mg}$ phosphorus/ square meterday, and the total phosphorus emissions from sediment release and other internal sources are 13.5 $\mathrm{mg}$ phosphorus/ square meter-day. The impact of external pollution on the water quality of Tonggu Lake is greater than that of internal sediment release. Therefore, measures should be taken to control and reduce external pollution. We can further calculate through that: if the total phosphorus treatment emission from external sources reaches Class A standard, the water quality of Tonggu Lake can basically eliminate the inferior Class V (TP: 0.19 $\mathrm{mg} / \mathrm{L}$ ); if both internal and external pollution are controlled, the water quality of Tonggu Lake can be maintained at Class IV-V (TP: $0.15 \mathrm{mg} / \mathrm{L}$ ).

According to the sampling and monitoring survey of external and internal pollution, the pollution caused by the sediment in the internal pollution is higher at the estuary of the Tonggu Lake lake than the estuary, and the the pollution caused by the sediment in the internal pollution is higher at the estuary of the Tonggu Lake lake than the 
estuary. This requires targeted treatment in the environmental improvement design of Tonggu Lake in the later stages of the environment aiming at the difference in pollution caused by external pollution and internal pollution in the geographical space of Tonggu Lake.
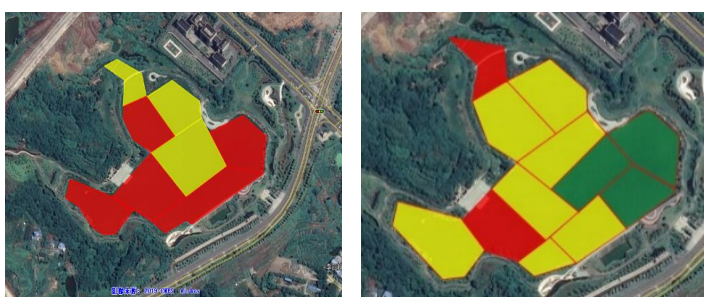

Figure 5. Zoning of external and internal pollution of Tonggu Lake

\section{Conclusion}

The water bloom phenomenon in Tonggu Lake has both external and internal causes. This study made a specific diagnosis. It is necessary to combine pollution characteristics of Tonggu Lake, and adopt external pollution control, internal pollution control, water quality improvement, water ecosystem construction and emergency measures to improve the water environment of Tonggu Lake in general.

\section{Acknowledgments:}

1. Fund Project: "Research on the Application of Prefabricated integrated pipe gallery in engineering" Science and Technology Research project of Chongqing Education Commission in 2018 (KJQN201804307)

\section{References}

1. Mei Cai, Yuanyuan Wang, Lili Gong, Haiyang Xu. Thoughts and suggestisons on a new round of comprehensive management of water environment in Taihu Lake Basin $[\mathrm{J}]$. Water conservancy planning and design,2021.2.

2. Yang Li. Analysis of water environment in Panjing River Basin and Research on Countermeasures [J] . Jouranl of Green Sicence and Technology, Volume 23 issue 2, 2021

3. Xinyue Pang. Ideas and measures of water environment control in Bidao construction of Guangzhou City[J]. Guangdong Water resource and hydropower,Phase 2, 2021

4. Jing Zhang, Hua Zheng, Mengnan He, Jinfeng Ma. Simulation of water environmental pollution and identification of key source areas in River Basin-A case study of Yiwu River Basin $[\mathrm{J}]$. Journal of environmental engineering,Feb 2021.

5. General Administration of quality supervision, inspection and Quarantine of the people's Republic of China GB3838-2002 Environmental Quality Standards for Surface Water [S]. China Environmental Science Press, 4,2002 